\title{
Preoperative Inhalation of Milrinone Attenuates Inflammation in Patients Undergoing Cardiac Surgery with Cardiopulmonary Bypass
}

\author{
Ming Gong ${ }^{a}$ Xue-Zheng Lin ${ }^{b}$ Guang-Tao Lu ${ }^{b}$ Li-Juan Zheng ${ }^{b}$ \\ a Department of Anesthesiology, Second Affiliated Hospital, School of Medicine, Zhejiang University, Hangzhou, \\ and ${ }^{\mathrm{b}}$ Department of Anesthesiology, Taizhou Central Hospital, Taizhou, China
}

\section{Key Words}

Milrinone inhalation $\cdot$ Cardiac surgery $\cdot$ Inflammation

\begin{abstract}
Objectives: The purpose of this study was to evaluate the effect of preoperative inhalation of milrinone on cardiopulmonary bypass (CPB)-related inflammation. Subjects and Methods: A total of 30 patients undergoing cardiac surgery were recruited and randomized for preoperative inhalation of milrinone (Mil group) or normal saline (NS group), respectively. Each group had 15 patients. Their hemodynamic parameters were measured and blood samples were obtained longitudinally. The levels of serum interleukin (IL-6), tumor necrosis factor- $\alpha$ (TNF- $\alpha$ ), and matrix metalloproteinase (MMP)-9 were determined by ELISA. Results: The levels of serum IL-6, TNF- $\alpha$, and MMP-9 significantly increased the end of cardiac surgery and remained high for $24 \mathrm{~h}$ in both groups of patients. However, the levels of proinflammatory cytokines at the end of cardiac surgery in the Mil group of patients were significantly lower than those of the NS group of patients. Conclusions: Our data indicated that preoperative inhalation of milrinone significantly mitigated CPB-related inflammation.

Copyright $\odot 2011$ S. Karger AG, Basel
\end{abstract}

\section{Introduction}

Cardiac surgery with cardiopulmonary bypass (CPB) is usually associated with the development of acute inflammation, which has important clinical implications [1]. An uncontrolled inflammation may lead to the development of postoperative complications, including respiratory failure, renal dysfunction, bleeding disorders, neurologic dysfunction, altered liver function, and ultimately, multiple organ failure [2]. Numerous strategies to minimize the impact of inflammation on cardiac surgical patients have been employed, and they include new pharmacologic agents, $\mathrm{CPB}$ circuits and components (i.e. heparin-coated system, leukocyte filters), and procedures avoiding CPB (off-pump technique) [3]. Despite significant changes and improvements in surgical techniques, $\mathrm{CBP}$-associated inflammation remains a challenge in the management of surgical patients.

Cyclic adenosine monophosphate (cAMP) has been considered to have general anti-inflammatory activity, and previous studies have shown that pharmacologic agents, which can elevate the levels of intracellular cAMP, can inhibit inflammation-related chemotaxis, lysosomal enzyme and histamine release, mitogenesis, and lym-

\section{KARGER}

Fax +4161306 1234

E-Mail karger@karger.ch

www.karger.com
(C) 2011 S. Karger AG, Basel

1011-7571/12/0211-0030\$38.00/0

Accessible online at:

www.karger.com/mpp
Xue-Zheng Lin

Department of Anesthesiology

Taizhou Central Hospital

Taizhou (China)

Tel. +86 5768852 6155, E-Mail doctorgm@163.com 
phocyte-mediated cytotoxicity $[4,5]$. Phosphodiesterase (PDE3) inhibitors can increase intracellular cAMP by inhibition of phosphodiesterase enzyme [6,7]. Various studies have demonstrated that PDE3 inhibitor could mitigate lipopolysaccharide-induced endothelial injury and inflammation, and promote postischemic recovery in tissues and organs [8-11].

Milrinone is a PDE3 inhibitor and enhances cardiac contractility [7, 12]. Intravenous administration with milrinone has been commonly used for the postoperative treatment of patients with myocardial dysfunction after CPB [12]. However, intravenous administration usually lacks pulmonary specificity and thus has undesirable adverse effects, such as systemic hypotension $[7,12]$. Our previous study has shown that inhalation of milrinone can effectively induce pulmonary vasodilation with little adverse systemic effect and appears to be a promising alternative approach in reducing post-CPB-related right ventricular decompensation [13]. Given that milrinone is a PDE3 inhibitor and can elevate the intracellular levels of cAMP, we decided to investigate whether or not the inhalation of milrinone could mitigate CPB-related inflammation.

\section{Subjects and Methods}

\section{Subjects}

A total of 30 patients undergoing rheumatic heart disease surgery with $\mathrm{CPB}$ were recruited at Taizhou Central Hospital from March 2007 to December 2009. Individual patients who had a history of chronic obstructive pulmonary disease, left ventricular ejection fraction $<40 \%$, any of the inflammatory diseases, such as type 1 diabetes, rheumatoid arthritis, multiple sclerosis, tuberculosis, or recent infection were excluded. In addition, individuals who continually used corticosteroid or nonsteroidal anti-inflammatory substances during the past 3 months were also excluded. Their demographic characteristics were surveyed by physicians. Written informed consent was obtained from all patients, and the experimental protocol was reviewed and approved by the Ethics Committee of Taizhou Central Hospital, China.

\section{Anesthesia and Treatment}

Patients were randomly divided into two groups by using sealed envelopes. One group (Mil, $n=15$ ) of patients received the nebulized milrinone and the other group (NS, $n=15)$ received nebulized normal saline. All the patients were pretreated orally with $5 \mathrm{mg}$ diazepam on the night before surgery. In the operation room, the patients were routinely monitored for pulse oximetry, noninvasive blood pressure, mean arterial pressure, and electrocardiogram.

Before general anesthesia, the patients in the Mil group inhaled $15 \mathrm{ml}$ of $0.1 \%$ milrinone (dissolved in normal saline) at a rate of $1.0 \mathrm{ml} / \mathrm{min}$ for $15 \mathrm{~min}$ using an ultrasonic nebulizer (Yuyue-
402AI, Jiangshu, China) through the mask over the patients' mouth and nose. The NS group of patients inhaled $15 \mathrm{ml}$ of normal saline from a nebulizer. Subsequently, the patients were intravenously administered etomidate, midazolam, sufentanil, and rocuronium for induction of anesthesia, and maintained with a continuous infusion of propofol throughout the operation. $\mathrm{Pa}$ tients were treated with bolus doses of sufentanil and rocuronium during the $\mathrm{CPB}$ procedure using a nonpulsatile pump and a membrane oxygenator. In addition, the patients were treated with heparin $(300 \mathrm{IU} / \mathrm{kg})$ for induction of systemic heparinization before $\mathrm{CPB}$ and with protamine (1:1) at the end of surgery for reversal. The patients were maintained at moderate systemic hypothermia $\left(28-30^{\circ} \mathrm{C}\right)$ for the $\mathrm{CPB}$ procedure with a continuous flow of $2-$ $2.5 \mathrm{l} / \mathrm{min} / \mathrm{m}^{2}$ and a perfusion pressure between 50 and $70 \mathrm{~mm} \mathrm{Hg}$. Moreover, myocardial protection was achieved by intermittent hyperkalemic cold crystalloid cardioplegia and topical hypothermia.

\section{Measurements}

Blood samples were obtained from individual patients at four points in time: T0, baseline (before inhalation); T1, immediately before starting CPB; T2, at the end of surgery; and T3, $24 \mathrm{~h}$ after surgery. Their sera were prepared by centrifuging, and were aliquoted and stored at $-30^{\circ} \mathrm{C}$ until use.

Cytokines like interleukin (IL-6) and tumor necrosis factor (TNF)- $\alpha$ were analyzed using enzyme-linked immunosorbent assay (ELISA, Diagnostic Product Corp., Los Angeles, Calif., USA). The concentrations of serum matrix metalloproteinase (MMP-9) were determined by sandwich ELISA reagent kits, according to the manufacturer's instructions (R\&D Systems, Minneapolis, Minn., USA).

\section{Statistical Analysis}

Statistical procedures were performed using the Statistical Package for the Social Sciences (SPSS 15.0, SPSS Inc., Chicago, Ill., USA). Data are expressed as mean \pm standard deviation. After confirming the normal distribution of all variables, overall differences between groups over the whole study period were analyzed using one-way ANOVA. Only if significant overall differences were detected, a two-way ANOVA for repeated measurements with group and time as factors was performed to analyze the different time points within and between groups using appropriate post hoc comparisons (Student-Newman-Keuls test); $\mathrm{p}$ values $<0.05$ were considered statistically significant.

\section{Results}

The demographic and clinical characteristics of the 30 patients are described in table 1 . There was no significant difference in age, gender, weight, height, the surgical intervention, the time for $\mathrm{CPB}$, and cross-clamp between the two groups $(p>0.05)$. During the cardiac operation, there was no significant difference in heart rate, artery blood pressure, and cardiac index between these two groups. There was also no significant difference in the time until extubation and duration in the ICU and hos- 


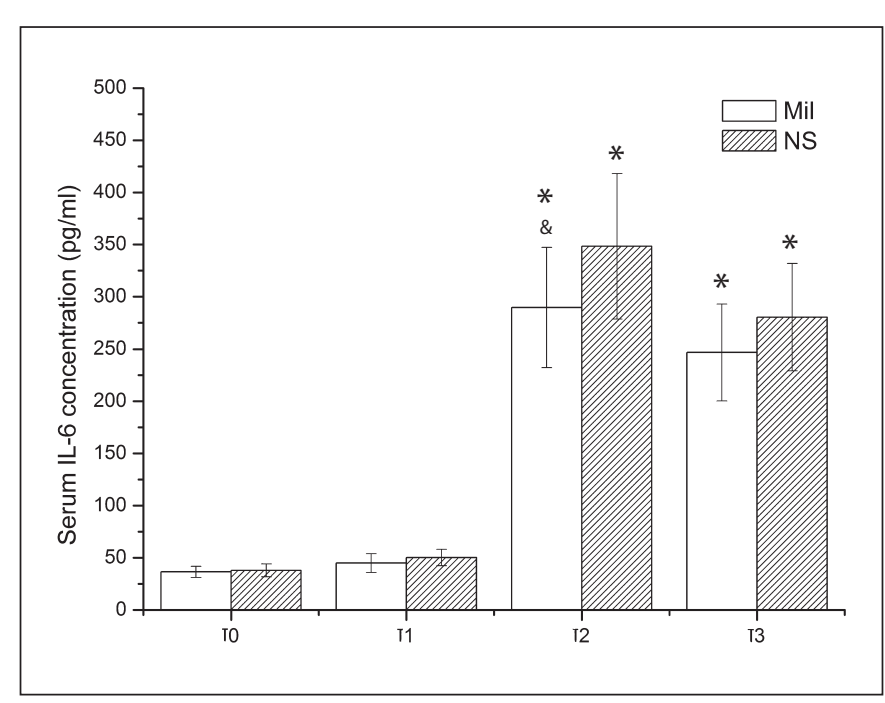

Fig. 1. Levels of serum IL- $6 . \mathrm{T} 0=$ Baseline; $\mathrm{T} 1=$ immediately before starting surgery; T2 $=$ at the end of surgery; $\mathrm{T} 3=24 \mathrm{~h}$ after surgery. ${ }^{*} \mathrm{p}<0.01$ compared with baseline; ${ }^{\&} \mathrm{p}<0.05$ compared with NS group.

pital between the two groups of patients. All patients survived with no mortality and serious postoperative complications in both groups up to being discharged from the hospitals.

The levels of serum IL- 6 and TNF- $\alpha$ in both groups of patients are shown in figures 1 and 2 . Following the procedure of $\mathrm{CPB}$, at the end of surgery, IL- 6 and TNF- $\alpha$ levels were found to have increased by several-fold ( $\mathrm{p}<$ 0.01 ), were significantly higher than baseline values, and remained at high levels for at least $24 \mathrm{~h}$ after surgery in both groups. In the Mil group, IL-6 increased from 36.5 $\pm 5.3 \mathrm{pg} / \mathrm{ml}$ at baseline to $289.8 \pm 57.5 \mathrm{pg} / \mathrm{ml}$ at the end of surgery, TNF- $\alpha$ increased from $251.3 \pm 46.2 \mathrm{pg} / \mathrm{ml}$ at baseline to $521.2 \pm 78.9 \mathrm{pg} / \mathrm{ml}$ at the end of surgery. In the NS group, IL- 6 increased from $37.9 \pm 6.1 \mathrm{pg} / \mathrm{ml}$ at baseline to $348.3 \pm 69.6 \mathrm{pg} / \mathrm{ml}$ at the end of surgery, TNF- $\alpha$ increased from $223.8 \pm 32.9 \mathrm{pg} / \mathrm{ml}$ at baseline to $602.5 \pm 92.1 \mathrm{pg} / \mathrm{ml}$ at the end of surgery. Interestingly, the levels of IL- 6 and TNF- $\alpha$ in the Mil group of patients were significantly lower than those of the NS group of patients at the end of surgery $(\mathrm{p}<0.05)$, although there was no significant difference in the levels of serum IL-6 between these two groups of patients at $24 \mathrm{~h}$ after surgery.

Analysis of the concentrations of serum MMP-9 revealed significantly increased levels of serum MMP-9 at the end of surgery and $24 \mathrm{~h}$ after surgery in both groups

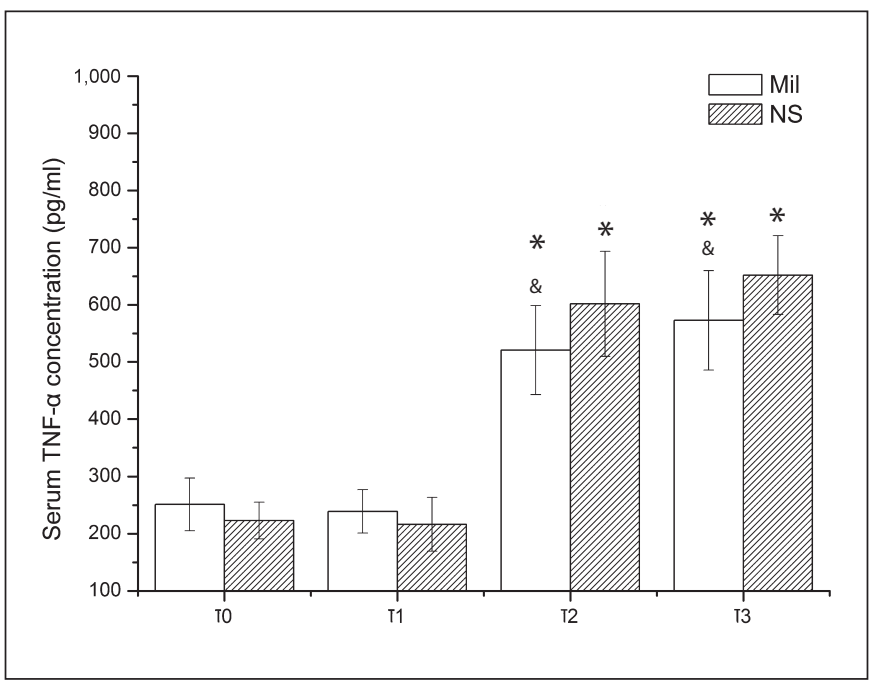

Fig. 2. Levels of serum TNF- $\alpha$. T0 = Baseline; $\mathrm{T} 1=$ immediately before starting surgery; T2 $=$ at the end of surgery; $\mathrm{T} 3=24 \mathrm{~h}$ after surgery. ${ }^{*} \mathrm{p}<0.01$ compared with baseline; ${ }^{8} \mathrm{p}<0.05$ compared with NS group.

Table 1. Demographic and perioperative characteristics of patients

\begin{tabular}{lcc}
\hline & $\begin{array}{l}\text { Mil group } \\
(\mathrm{n}=15)\end{array}$ & $\begin{array}{l}\text { NS group } \\
(\mathrm{n}=15)\end{array}$ \\
\hline Age, years & $45.86 \pm 7.51$ & $48.59 \pm 10.16$ \\
Weight, kg & $60.21 \pm 9.25$ & $58.3 \pm 10.28$ \\
Height, cm & $163.3 \pm 8.32$ & $165.9 \pm 9.35$ \\
Gender, male/female & $6 / 9$ & $5 / 10$ \\
Cross-clamp time, min & $62.2 \pm 13.3$ & $57.6 \pm 12.5$ \\
CPB time, min & $120.1 \pm 23.9$ & $110.7 \pm 24.8$ \\
Operation, M/A/MA & $8 / 4 / 3$ & $6 / 4 / 5$ \\
Time until extubation, $h$ & $8.6 \pm 4.3$ & $8.8 \pm 4.6$ \\
Duration in the ICU, $\mathrm{h}$ & $53.6 \pm 10.7$ & $51.9 \pm 11.3$ \\
& &
\end{tabular}

$\mathrm{M}=$ Mitral valve replacement; $\mathrm{A}=$ aortic valve replacement; $\mathrm{MA}=$ mitral and aortic valve replacement.

of patients (fig. 3). In the Mil group, MMP-9 increased from $45.9 \pm 7.8 \mathrm{ng} / \mathrm{ml}$ at baseline to $95.2 \pm 22.9 \mathrm{ng} / \mathrm{ml}$ at the end of surgery. In the NS group, MMP-9 increased from $51.1 \pm 6.9 \mathrm{ng} / \mathrm{ml}$ at baseline to $121.8 \pm 32.6 \mathrm{ng} / \mathrm{ml}$ at the end of surgery. More importantly, the concentrations of serum MMP-9 at the end of surgery in the Mil group of patients were significantly lower than those of the NS group $(p<0.05)$, although there was no significant 


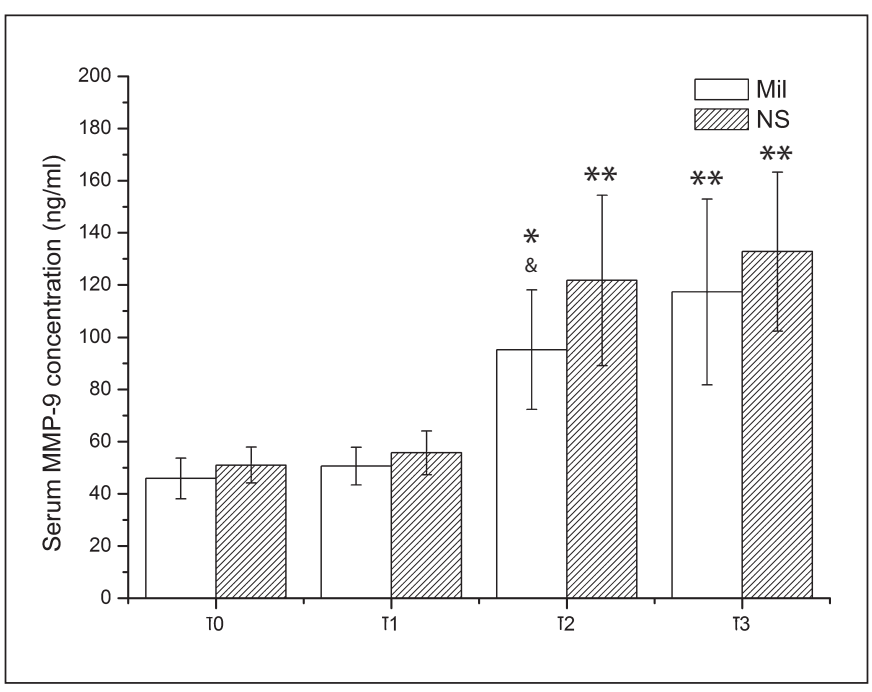

Fig. 3. Levels of serum MMP-9. T0 = Baseline; T1 = immediately before surgery; $\mathrm{T} 2=$ at the end of surgery; $\mathrm{T} 3=24 \mathrm{~h}$ after surgery. ${ }^{*} \mathrm{p}<0.05,{ }^{* *} \mathrm{p}<0.01$ compared with baseline; ${ }^{\&} \mathrm{p}<0.05$ compared with NS group.

difference in the levels of serum MMP-9 between the two groups of patients at $24 \mathrm{~h}$ after surgery. Collectively, inhalation of milrinone reduced the CPB-related acute inflammation in those patients.

\section{Discussion}

Our data indicated that preoperative inhalation of milrinone significantly mitigated the CPB-related inflammation by inhibiting the production of proinflammatory cytokines, such as IL-6, TNF- $\alpha$, and MMP-9 in patients undergoing cardiac surgery with $\mathrm{CPB}$.

The CPB procedure is associated with the development of inflammation, accompanied by the production of proinflammatory cytokines. IL- 6 and TNF- $\alpha$ can play a significant role in stimulating and coordinating the inflammatory process $[14,15]$. IL- 6 is recognized as an early and robust marker of surgery-related systemic inflammation [14]. We found that the levels of serum IL- 6 and TNF- $\alpha$ significantly increased at the end of cardiac surgery, and were maintained at high levels for at least $24 \mathrm{~h}$ in both groups of patients. These data support the notion that $\mathrm{CPB}$-related inflammation stimulates the production of proinflammatory cy tokines in patients. The CPBrelated systemic inflammation has been attributed to the contact of blood components with synthetic material in the extracorporeal circulation circuit, and the ischemia and reperfusion-induced activation of leukocytes and endothelial cells [16].

Several studies have indicated that intravenous administration of milrinone inhibits cardiac surgery-related inflammation in experimental rodents and in patients $[8,10,17]$. Treatment with milrinone inhibits lipopolysaccharide-induced TNF- $\alpha$ production by cultured rat cardiac tissues in vitro [17]. In a prospective randomized clinical study, intravenous administration of milrinone reduced the levels of serum proinflammatory cytokines in patients who underwent the $\mathrm{CPB}$ procedure [8]. In this study, the levels of serum IL- 6 and TNF- $\alpha$ at the end of surgery in the Mil group of patients were significantly lower than those of the NS group. Evidently, preoperative inhalation of milrinone inhibited the CPB-related proinflammatory cytokine production. Apparently, significantly reduced production of proinflammatory cytokines should be of benefit to patient recovery after surgery.

The application of CPB in cardiac surgery may be associated with pulmonary inflammation. Under the conditions of CPB and aortic cross-clamping, both heart and lung are excluded from the circulation. The blood supply of the lung consists of two circulatory systems: the pulmonary circulation and the bronchial circulation [18]. During CPB, blood flow to the lung is limited to flow through the bronchial arteries. The reduction in bronchial arterial blood flow by $\mathrm{CPB}$ has been associated with lung injury [19]. After CPB, reperfusion of the heart and lungs can also induce an inflammatory response [19]. Although the myocardium is generally protected by cardioplegia, there is no specific approach for protecting the lungs in the $\mathrm{CPB}$ procedure.

Milrinone is a phosphodiesterase inhibitor and has the potential for immunomodulation by inhibiting intracellular cyclic nucleotide phosphodiesterase, thus increasing the intracellular concentrations of cAMP $[4,5]$. Inhalation of milrinone is thought to predominantly affect the pulmonary circulation. Indeed, a previous study had demonstrated that inhalation of milrinone significantly elevated the levels of cAMP in the pulmonary arteries of pigs [20]. Elevated levels of cAMP can strengthen the microvascular barrier, increase alveolar fluid clearance, attenuate neutrophil adhesion and migration, and protect the lungs against various injuries $[9,10,21,22]$. In this study, we measured the serum level of MMP-9 to investigate whether or not the inhalation of milrinone could attenuate the CPB-related lung injury. MMP-9, also called gelatinase $\mathrm{B}$, is mainly produced by inflammatory cells, 
such as neutrophils, monocytes/macrophages, and eosinophils $[23,24]$. It is well documented that MMP-9 plays an important role in pulmonary injury [25-27]. During an acute inflammatory response, neutrophils can migrate to the inflammatory site and produce MMP-9, which in turn degrades type IV collagen, the major constituent of basement membrane, and facilitates neutrophil extravasation [24]. Furthermore, increased levels of serum MMP-9 have been detected in patients with the CPB procedure [25-27]. In addition, the inhibition of MMP-9 has been demonstrated to protect against the development of neutrophilmediated inflammation in the lung $[28,29]$. The preoperative inhalation of milrinone significantly reduced the levels of serum MMP-9 in patients at the end of surgery, as compared with that in the NS group of patients, which indicated that the preoperative inhalation of milrinone mitigated the ischemia-reperfusion lung injury in patients undergoing cardiac surgery with CPB.

A major limitation of this study was the inability to precisely measure the exact dose of milrinone reaching the alveolar space because of the potential loss in the nebulizer chamber, face mask, and upper respiratory tract. Secondly, the current study had a small sample size so we could have missed potential side effects of milrinone administration, such as ventricular arrhythmias and thrombocytopenia. We are interested in further evaluating the therapeutic efficacy and safety of milrinone inhalation in more patients undergoing cardiac surgery with CPB.

\section{Conclusion}

Our findings indicate that milrinone mitigated the CPB-related inflammation in patients undergoing cardiac surgery and $\mathrm{CPB}$ procedures. Therefore, the preoperative inhalation of milrinone may be a promising approach for minimizing the impact of inflammation on cardiac surgery patients.

\section{References}

-1 Suleiman MS, Zacharowski K, Angelini GD: Inflammatory response and cardioprotection during open-heart surgery: the importance of anaesthetics. Br J Pharmacol 2008; 153:21-33.

-2 Taylor KM: SIRS - the systemic inflammatory response syndrome after cardiac operations. Ann Thorac Surg 1996;61:16071608.

3 Raja SG, Dreyfus GD: Modulation of systemic inflammatory response after cardiac surgery. Asian Cardiovasc Thorac Ann 2005; 13: 382-395.

$\checkmark 4$ Moore AR, Willoughby DA: The role of cAMP regulation in controlling inflammation. Clin Exp Immunol 1995; 101:387-389.

5 Bourne HR, Lichtenstein LM, Melmon KL, Henney CS, Weinstein Y, Shearer GM: Modulation of inflammation and immunity by cyclic AMP. Science 1974;184:19-28.

$\checkmark 6$ Bender AT, Beavo JA: Cyclic nucleotide phosphodiesterases: molecular regulation to clinical use. Pharmacol Rev 2006;58:488520.

7 Lehtonen LA, Antila S, Pentikäinen PJ: Pharmacokinetics and pharmacodynamics of intravenous inotropic agents. Clin Pharmacokinet 2004;43:187-203.

$>8$ Hayashida N, Tomoeda H, Oda T, Tayama E, Chihara S, Kawara T, Aoyagi S: Inhibitory effect of milrinone on cytokine production after cardiopulmonary bypass. Ann Thorac Surg 1999;68:1661-1667.
9 Blease K, Burke-Gaffney A, Hellewell PG: Modulation of cell adhesion molecule expression and function on human lung microvascular endothelial cells by inhibition of phosphodiesterases 3 and 4. Br J Pharmacol 1998;124:229-237.

10 Irie K, Fujii E, Ishida H, Wada K, Suganuma T, Nishikori T, Yoshioka T, Muraki T: Inhib itory effects of cyclic AMP elevating agents on lipopolysaccharide (LPS)-induced microvascular permeability change in mouse skin. Br J Pharmacol 2001;133:237-242.

-11 Iba T, Kidokoro A, Fukunaga M, Takuhiro K, Ouchi M, Ito Y: Comparison of the protective effects of type III phosphodiesterase (PDE3) inhibitor (cilostazol) and acetylsalicylic acid on intestinal microcirculation after ischemia reperfusion injury in mice. Shock 2006;26:522-526.

12 Levy JH, Bailey JM, Deeb GM: Intravenous milrinone in cardiac surgery. Ann Thorac Surg 2002;73:325-330.

13 Wang H, Gong M, Zhou B, Dai A: Comparison of inhaled and intravenous milrinone in patients with pulmonary hypertension undergoing mitral valve surgery. Adv Ther 2009;26:462-468.

- 14 Cruickshank AM, Fraser WD, Burns HJ, Van Damme J, Shenkin A: Response of serum interleukin-6 in patients undergoing elective surgery of varying severity. Clin Sci 1990;79:161-165.
$>15$ Dinarello CA, Gelfand JA, Wolff SM: Anticytokine strategies in the treatment of the systemic inflammatory response syndrome. JAMA 1993;269:1829-1835.

16 Asimakopoulos G: Systemic inflammation and cardiac surgery: an update. Perfusion 2001;16:353-360.

17 Bergman MR, Holycross BJ: Pharmacological modulation of myocardial tumor necrosis factor alpha production by phosphodiesterase inhibitors. J Pharmacol Exp Ther 1996;279:247-254.

18 Schlensak C, Doenst T, Preusser S, Wunderlich M, Kleinschmidt M, Beyersdorf F: Cardiopulmonary bypass reduction of bronchial blood flow: a potential mechanism for lung injury in a neonatal pig model. J Thorac Cardiovasc Surg 2002;123:11991205.

19 Schlensak C, Doenst T, Preusser S, Wunderlich M, Kleinschmidt M, Beyersdorf F: Bronchial artery perfusion during cardiopulmonary bypass does not prevent ischemia of the lung in piglets: assessment of bronchial artery blood flow with fluorescent microspheres. Eur J Cardiothorac Surg 2001; 19:326-331.

20 Lamarche Y, Malo O, Thorin E, Denault A, Carrier M, Roy J, Perrault LP: Inhaled but not intravenous milrinone prevents pulmonary endothelial dysfunction after cardiopulmonary bypass. J Thorac Cardiovasc Surg 2005;130:83-92. 
-21 Chen F, Nakamura T, Fujinaga T, Zhang J, Hamakawa H, Omasa M, Sakai H, Hanaoka N, Bando T, Wada H, Fukuse T: Protective effect of a nebulized beta $_{2}$-adrenoreceptor agonist in warm ischemic-reperfused rat lungs. Ann Thorac Surg 2006;82:465-471.

-22 Hoffmann SC, Bleiweis MS, Jones DR, Paik HC, Ciriaco P, Egan TM: Maintenance of cAMP in non-heart-beating donor lungs reduces ischemia-reperfusion injury. Am J Respir Crit Care Med 2001;163:1642-1647.

23 Bueltmann M, Kong X, Mertens M, Yin N, Yin J, Liu Z, Koster A, Kuppe H, Kuebler WM: Inhaled milrinone attenuates experimental acute lung injury. Intensive Care Med 2009;35:171-178.
24 Emonard H, Grimaud JA: Matrix metalloproteinases: a review. Cell Mol Biol 1990;36: 131-153.

25 Johnson LL, Dyer R, Hupe DJ: Matrix metalloproteinases. Curr Opin Chem Biol 1998;2: 466-471.

26 Lin TC, Li CY, Tsai CS, Ku CH, Wu CT, Wong CS, Ho ST: Neutrophil-mediated secretion and activation of matrix metalloproteinase-9 during cardiac surgery with cardiopulmonary bypass. Anesth Analg 2005; 100:1554-1560.

27 Steinberg J, Fink G, Picone A, Searles B, Schiller H, Lee HM, Nieman G: Evidence of increased matrix metalloproteinase-9 concentration in patients following cardiopulmonary bypass. J Extra Corpor Technol 2001;33:218-222.
28 Fligiel SE, Standiford T, Fligiel HM, Tashkin D, Strieter RM, Warner RL, Johnson KJ, Varani J: Matrix metalloproteinases and matrix metalloproteinase inhibitors in acute lung injury. Hum Pathol 2006;37:422-430.

29 Kim JH, Suk MH, Yoon DW, Lee SH, Hur GY, Jung KH, Jeong HC, Lee SY, Lee SY, Suh IB, Shin C, Shim JJ, In KH, Yoo SH, Kang $\mathrm{KH}$ : Inhibition of matrix metalloproteinase-9 prevents neutrophilic inflammation in ventilator-induced lung injury. Am J Physiol Lung Cell Mol Physiol 2006; 291:L580-L587. 